\title{
Blogs as a Teaching Tool and Method of Public Legal Education: A Case Study* \\ Victoria Roper
}

Key Words: blog, business clinic, clinical legal education, legal education, public legal education, social media

\section{Introduction}

Social media, and blogs specifically, can potentially have a dual raison d'etre: enriching a law student's educational experience whilst simultaneously educating the general public. Through a case study analysis of a blog project employed in a clinical legal education module at Northumbria University, the opportunities, challenges and limitations of using blogs in this way will be explored from both a pedagogical and public legal education perspective.

\section{The Opportunities}

Social media and blogs

The Law Society of England and Wales describes social media as 'websites and applications that enable users to create and share content or to 
participate in social networking'. ${ }^{1}$ It comes in a wide range of forms including social networking sites (e.g. Facebook, LinkedIn), weblogs, micro-blogging sites (Twitter, Tumblr etc.) and other interactive forums and discussion boards. Facebook ${ }^{2}$ continues to be the largest social networking service in the UK followed by Twitter ${ }^{3}$ and then LinkedIn ${ }^{4}$. Facebook has 40.7 million users, Twitter 21.6 million users and LinkedIn 20.7 million users respectively. ${ }^{5}$ Blogs are also very popular (being regularly updated web pages 'consisting of several posts or distinct chunks of information per page, usually arranged in reverse chronological order') ${ }^{6}$ There are many legal blogs, sometimes referred to as 'blawgs, covering matters relating to the law. ${ }^{7}$ Services like WordPress ${ }^{8}$ allow people to set up and maintain blogs with relative ease. WordPress has grown to be the most used blogging tool in the world with over 60 million websites, its

\footnotetext{
* Victoria Roper is a Senior Lecturer at Northumbria University in the United Kingdom.

${ }^{1}$ See http://www.lawsociety.org.uk/support-services/advice/practice-notes/social-media/ (accessed 24 November 2017).

${ }^{2}$ Facebook is a free website that allows users to create profiles and share photos and videos and socialise with friends and family members.

${ }^{3}$ Twitter is a micro-blog. Registered users can make posts, referred to as 'tweets', of up to 280 characters in length. It is possible to follow other registered users.

${ }^{4}$ Linkedln is a social networking site designed primarily for business networking. Users create profiles and can then connect to their contacts through the site.

${ }^{5}$ Ofcom, The communications Market Report (2015) at p.361 available at http://stakeholders.ofcom.org.uk/binaries/research/cmr/cmr15/CMR UK 2015.pdf (accessed 27 November 2017).

${ }^{6}$ P. Bausch, M. Haughey and M. Hourihan, We Blog (Wiley Publishing, 2002) at p. 7.

7 P. Black, 'Uses of blogs in legal education' (2006) 13 James Cook University Law Review 8 at p.13.

${ }^{8}$ See https://wordpress.com/ (accessed 24 November 2017).
} 
popularity no doubt attributable in part to the fact it does not charge for most of its services. ${ }^{9}$

How can blogs be used in legal teaching?

Blogs are quite a flexible tool and can be adapted to suit a user's requirements. They may be created and maintained by one person (such as a lecturer) but they can also be managed by a small group of people or involve large communities of contributors. ${ }^{10}$ A lecturer might set up and maintain a blog as a way of communicating with students, posting relevant material to the blog site (legal updates, links to relevant webpages etc.) and giving students the ability to make comments and ask questions. ${ }^{11}$ It is also possible to set up blog networks, where, for example, the lecturer and each student has their own blog for teaching and learning purposes. ${ }^{12}$ In addition to the content and functionality envisaged with a lecturer maintained blog, the additional purpose of the blog network is to allow students to develop a reflective journal of sorts and to receive comments from their lecturer and their peers. ${ }^{13}$ These types of blog have a learning and teaching focus and accordingly the intended readers of the blog(s) are primarily all part of the relevant teaching module. However, as the following Northumbria

\footnotetext{
${ }^{9}$ See http://www.forbes.com/sites/jicolao/2012/09/05/the-internets-mothertongue/\#53e6734055fe (accessed 17 February 2016).

${ }^{10}$ P. Black, 'Uses of blogs in legal education' (2006) 13 James Cook University Law Review 8 at p. 9.

${ }^{11} \mathrm{lbid}, \mathrm{p} .16$.

12 Ibid. p. 17.

${ }^{13} \mathrm{lbid}$.
} 
University case study will illustrate, another form of blog is where law students are the primary content creators, writing posts with the specific intention of these being read by individuals external to the university. As well as potentially being of educational value, this type of blog is also more aligned to a public legal education agenda (discussed further below).

\section{Northumbria University Case Study}

The Student Law Office

Northumbria University has one of the longest running live-client law clinics in the United Kingdom (UK) ${ }^{14}$. All students enrolled on the four-year M Law Exempting law degree ${ }^{15}$ must undertake a year-long assessed clinical module, known as Student Law Office (SLO), in their final year. The students provide a free advice service to members of the public under the supervision of qualified practitioners. Approximately 20 solicitors, barristers and caseworkers supervise an average of 170 students each academic year in the SLO who provide advice and representation to the general public. Students work in teams of six, referred to as 'firms' which

\footnotetext{
${ }^{14} \mathrm{~J}$. Hall, C. Sylvester and E. Hall, 'Problem-based learning and clinical legal education: What can clinical educators learn from PBL?' (2004) International Journal of Clinical Legal Education 4 at $\mathrm{p}$. 40.

${ }^{15}$ This degree incorporates a qualifying law degree, a Master's degree, and exemption from the Legal Practice Course allowing a student to progress straight to their period of recognised training.
} 
specialise in their supervisor's area of expertise: civil litigation, crime, welfare benefits, employment, family etc. In 2007, the SLO established a specialist Business and Commercial Law Clinic. ${ }^{16}$ In the current academic year (2017-2018) twenty nine students worked in the Business and Commercial Law Clinic offering a range of advice and assistance to entrepreneurs, companies, charities and social enterprises. Typical enquiries include requests for advice in relation to corporate governance, intellectual property and contracts. The work is predominantly noncontentious. The blog project has been running in the Business and Commercial Law Clinic since autumn 2014.

\section{Blog project overview}

In the summer of 2014, the author and a colleague registered with WordPress, the free blog publisher discussed above, and created a blog using the web address https://wetakecareofbusiness.wordpress.com (the 'Blog'). The author and her colleague are the only people who have administrative rights to the Blog. They occasionally produce short editorial posts when the students are absent from the university, but it is the students themselves who mainly produce and direct the content. Constructivism suggests that students learn best when they are given the opportunity to

\footnotetext{
${ }^{16}$ E. Campbell, 'A dangerous method? Defending the rise of business law clinics in the UK' [2015] The Law Teacher 49:2, 165 at $\mathrm{p} 168$.
} 
build their own knowledge. ${ }^{17}$ In line with this theory, students are encouraged to decide for themselves what would be appropriate to write about and to build their knowledge by researching and writing their Blog posts without any significant lecturer input. Lecturers provide editorial oversight to ensure that any legal content is accurate however, a Blog post or idea has never been rejected and students are given a lot more creative freedom than they usually have in traditional teaching which is ordinarily more lecturer-led.

The Blog has the functionality to allow readers to make comments but we decided to disable this feature because we were concerned about having to constantly monitor comments. Whilst the SLO module is compulsory for all fourth year law students, the Blog is voluntary for those students who work in the Business and Commercial Clinic. Students are encouraged to get involved, they do not have to. The Blog itself is not credit-bearing but as students are assessed widely on activities undertaken in the SLO, with marks being given for their personal contribution to the SLO as well as their academic skills, any contribution towards the Blog can be taken into account in the overall mark they receive. ${ }^{18}$

\footnotetext{
${ }^{17}$ K. Exley and R. Dennick, Small Group Teaching: Tutorials, Seminars and Beyond (London, Routledge, 2004) at p.5.

${ }^{18}$ Students are assessed on their practical work evidenced by a portfolio $(70 \%$ of the overall mark) and by two reflective essays ( $30 \%$ of the overall mark).
} 
When we set up the Blog we hoped that it would have a pedagogic value and encourage the collaborative and constructivist learning environment discussed by Rambe and Nel, as students are responsible for choosing the topics they want to write about and for developing their own learning. ${ }^{19} \mathrm{We}$ also hoped they would gain an appreciation of the importance of maintaining a good social media image and the role social media can play in marketing and business development.

\section{Blog content}

When we set up the Blog we thought that students would predominantly write about legal topics they encountered in advising clients and this has proven to be the case. There is an 'Information for Businesses' tab on the Blog which helps direct readers to business related content. Topics students have chosen to write about include: choice of business ownership ${ }^{20}$; limited liability partnerships ${ }^{21}$; trade marks ${ }^{22}$; copyright ${ }^{23}$; the Small Business, Enterprise and Employment Act ${ }^{24}$; and the Consumer Rights $\mathrm{Act}^{25}$. As well

\footnotetext{
19 P. Rambe and L. Nel, 'Technological utopia, dystopia and ambivalence: Teaching with social media at a South African university' (2015) 46 British Journal of Educational Technology 629 at p. 630.

${ }^{20}$ See blog post dated 29 January 2016, 'Which Business Medium is Best for You?' available at https://wetakecareofbusiness.wordpress.com (accessed 27 November 2017).

${ }^{21}$ See blog post dated 11 January 2017, 'Limited Liability Partnerships: A New Way Forward'. Ibid.

22 See blog post dated 5 April 2016, 'Trade Marks 101: Part 2' and blog post dated 23 March 2016, “Trade Marks 101: Part 2'. Ibid.

${ }^{23}$ See blog post dated 20 April 2015, 'Keeping Yourself Informed in the Information Age: A Quick Guide to Copyright'. Ibid.

${ }^{24}$ See blog post dated 24 February 2016, 'The Small Business, Enterprise and Employment Act How Will it Affect You?'. Ibid.

${ }^{25}$ See blog post dated 19 January 2016, 'The Consumer Rights Act: Some Key Issues'. Ibid.
} 
as helping to consolidate and reflect on the knowledge the student has gained in the clinic, the Blog posts are available to the public and therefore have a public legal education aspect too. Some might question whether businesses and business people need educating about legal matters, but the author firmly believes that there is unmet legal need for businesses as there is for individuals. Small businesses in England and Wales often cannot afford to obtain legal advice and Business Link, the government funded network of local business advisors, was axed in 2011. ${ }^{26}$ The Solicitors Regulation Authority has reported that the majority of small businesses in England and Wales have little contact with legal providers and that over half of businesses that experienced a problem tried to resolve it on their own. ${ }^{27}$

The Blog is also designed to promote the work of the Business and Commercial Clinic in the same way a law firm might use social media to help attract clients ${ }^{28}$ and on occasion clients have been happy to take advantage of the free publicity and to feature in Blog posts with our students. When a new Blog post becomes available, we promote it through Twitter.

\footnotetext{
${ }^{26}$ See http://www.telegraph.co.uk/finance/yourbusiness/8093448/Business-Link-scrapped-andreplaced-by-call-centre.html (accessed 27 November 2017).

${ }^{27}$ Solicitors Regulation Authority, The Changing Legal Services Market (2015) at p. 16 available from www.sra.org.uk/risk/resources/changing-legal-services-market.page (accessed 27 November 2017).

${ }^{28}$ See, for example, the blog post dated 11 September 2017, 'Can We Help You?' available at https://wetakecareofbusiness.wordpress.com (accessed 27 November 2017).
} 
As well as writing about legal topics, students sometimes also choose to write about networking events they have attended and visits of important guests. Unexpectedly, students have also chosen to produce content which is aimed more at other students or legal practitioners. We have been impressed by our students' ability to be creative and to reflect on their studies and the wider legal profession. See for example the post entitled 'The Legal Hunger Games' (reflecting on the competitive nature of university generally ${ }^{29}$ or 'How is Artificial Intelligence Affecting the Legal Profession?' ${ }^{30}$. Commercial awareness, and how to acquire it, has also been a recurring theme. ${ }^{31}$ Acting on their own initiative, students have often worked collaboratively to produce posts, even on occasion working with students outside the Business and Commercial Clinic.

\section{Blog statistics}

To date the Blog has had over 7,000 views from people in over 100 countries so it is also clearly reaching an audience outside of the SLO and the wider University. ${ }^{32}$ As would be expected, the majority of viewers have been from the UK (approx. 78\%), followed by other English speaking countries such as the United States (approx. 9\%) and Australia (approx. 2\%). Whilst the

\footnotetext{
${ }^{29}$ See the post dated 17 March 2015. Ibid.

${ }^{30}$ See the post dated 23 March 2017. Ibid.

${ }^{31}$ See, for example, the post dated 2 March 2016, 'Are You Commercially Aware'. Ibid.

32 Data correct as at 11 June 2018 . WordPress automatically collects visitor data and it can be viewed by the relevant webpage administrator(s).
} 
limitations of this data are acknowledged below, the number of views and geographical spread support the view that blogs can potentially reach a very wide audience. This is potentially very useful from a public legal education perspective.

\section{Student engagement}

Despite the voluntary nature of the Blog, students have generally engaged well with it and to date we have worked with over 50 students. Informal student feedback from those who have engaged has been positive and indicates that students found it to be of value from both an educational perspective and also in terms of commercial awareness and employability (discussed further below). However, the author regrets not collecting data in a more systematic way, or specifically collecting data from those who did not engage to find out the reasons why. In subsequent projects the author has used an online survey to collect data. ${ }^{33}$ This has the advantage of automatically collating and displaying the survey results, allowing the researcher to avoid having to do this manually.

Other impact and success

In 2016 the Blog was shortlisted for the Routledge/ALT Teaching Law with Technology Prize 2016, a prize which 'rewards and champions innovation

\footnotetext{
33 The author's university has a subscription with Bristol Online Surveys https://www.onlinesurveys.ac.uk/ (accessed 27 November 2017).
} 
in teaching and learning'. ${ }^{34}$ Following the success of the Business and Commercial Firm Blog, the family law firms in the SLO have recently launched their own blog, 'A Family Affair' also using WordPress. ${ }^{35}$ At a recent legal clinic conference in Poland ${ }^{36}$, at which the author spoke about the Blog project, a number of delegates expressed an interest in starting to use blogs in their teaching.

Reflection is not just for students...

Whilst the author regards the Blog as an overall success, analysis of the project has highlighted a number of lessons to be learnt. The author acknowledges that a more formal method of gathering feedback should have been employed at the outset. Secondly, thought also needs to be given to the ethical considerations involved in adopting social media in teaching. A large-scale 2013 study of 251 colleges and universities students in the United States concluded that learners are sensitive to the boundaries between their personal and academic lives and using technology with them has its limits. ${ }^{37}$ This suggests that academics should avoid incorporating social media into legal education in a way that students may view as

\footnotetext{
${ }^{34}$ See https://www.routledge.com/law/posts/9620 (accessed 27 November 2017).

${ }^{35}$ See https://afamilyaffairsite.wordpress.com (accessed 27 November 2017).

${ }^{36}$ XXVIII Conference of Academic Legal Clinics, '20 years of Academic Legal Clinics in Poland achievements, future goals and development opportunities' (2017) Krakow, Poland. ${ }^{37}$ Educause Center for Analysis and Research, ECAR Study of Undergraduate Students and Information Technology (2013) at p.6 available at https://library.educause.edu/resources/2013/9/ecar-study-of-undergraduate-students-andinformation-technology-2013 (accessed 28 November 2017).
} 
intrusive. Having considered privacy issues, the author is of the view that that such concerns are valid and need to be addressed at the design stage of any teaching incorporating social media. The fact that such issues were not considered initially when the Blog project was implemented, highlights the importance of institutions adopting best practice policies and guidance. The voluntary nature of our Blog perhaps mitigates some of these concerns. However, any teaching design requiring students to set up their own social media accounts and/or with compulsory participation is potentially problematic. Thought also still needs to be given to privacy issues even if the use of social media is voluntary. Is it clear to the student that it really is voluntary? Might they be penalised in any way for not engaging?

\section{Potential Advantages of Using Blogs as a Teaching Tool and Method} of Public Legal Education

\section{Student learning and development}

As long ago as 2006 Black, writing from an Australian legal educator perspective, argued that 'blogs as an educational tool promote deep learning and critical, analytical and analogical thinking' ${ }^{38}$ There is a body of literature exploring the pedagogy of social media in education and Black's views could therefore be regarded as grounded in educational

38 P. Black, 'Uses of blogs in legal education' (2006) 13 James Cook University Law Review 8 at p. 29. 
theory. ${ }^{39}$ Cao et al. cite, amongst others, Bosman \& Zagenczyk who argue that social media can help achieve learning objectives. ${ }^{40}$ Evans has suggested that social media has many qualities that make it suitable for use in higher education including the fact it can promote knowledge sharing, collaboration and participation. ${ }^{41}$ Rambe and Nel point to various studies which appear to confirm that social media can have a positive impact on active learning and performance and state that social media's ability to support collaboration and social constructivist teaching is 'welldocumented'. ${ }^{42}$ Whilst a number of academics appear convinced, it is worth noting that some academics like Tess have suggested that the research on the effectiveness of social media in higher education, which would include blogs, is not fully supported by empirical data. ${ }^{43}$ The educational value of any learning and teaching activity will of course vary

\footnotetext{
${ }^{39}$ For a more detailed review of the relevant literature see for example Y. Cao, H. Ajjan and P. Hong, 'Using social media applications for educational outcomes in college teaching: A structural equation analysis' (2013) 44 British Journal of Educational Technology 581 or P. Rambe and L. Nel, 'Technological utopia, dystopia and ambivalence: Teaching with social media at a South African university' (2015) 46 British Journal of Educational Technology 629.

${ }^{40}$ Y. Cao, H. Ajjan and P. Hong, 'Using social media applications for educational outcomes in college teaching: A structural equation analysis' (2013) 44 British Journal of Educational Technology 581 citing L. Bosman and T. Zagenczyk, 'Revitalize your teaching: creative approaches to applying social media in the classroom. Social media tools and platforms in learning environments' in B. White, I. King, P. Tsang. (eds) Social Media Tools and Platforms in Learning Environments (Springer-Verlag Berlin Heidelberg, 2011).

${ }^{41} \mathrm{C}$. Evans, 'Twitter for teaching: Can social media be used to enhance the process of learning?' (2013) 45 British Journal of Educational Technology 902 at p. 902.

${ }^{42}$ P. Rambe and L. Nel, 'Technological utopia, dystopia and ambivalence: Teaching with social media at a South African university' (2015) 46 British Journal of Educational Technology 629 at p. 630.

${ }^{43} \mathrm{P}$. Tess, 'The role of social media in higher education classes (real and virtual) - A literature review' (2013) 29 Computers in Human Behavior A60 at A60.
} 
according to what students are required to do, the extent they engage, and how well tasks align with the lecturer's intended learning outcomes.

Our view, based on our experiences of the Blog project and student feedback, is that blogs can be of educational value to students. For example, some of our students have commented that writing blog posts helped them to understand the relevant legal issue more fully because it required them to concisely summarise the key issues. A recurring theme in the Student Law Office is that students find it difficult to adjust their academic writing to a style which a layperson, such as a client, would find accessible. As students know they will need to be able to master this skill if they wish to become a solicitor, some have commented that writing blog posts was useful practice in this regard.

Students have also told us that the blog has been something which they felt helped them to stand out in training contract and paralegal interviews. Law firms are very image conscious and increasingly use social media, blogs and newsletters to promote their services. The Law Society practice note on social media acknowledges that "social media is an increasingly popular and growing area...that can offer many professional...benefits". ${ }^{44}$ It suggests that social media can be used to engage with clients and to

\footnotetext{
${ }^{44}$ See http://www.lawsociety.org.uk/support-services/advice/practice-notes/social-media/ (accessed 17 February 2016).
} 
facilitate marketing and professional networking. Law firms are likely to value applicants who can demonstrate that they recognise this as an aspect of commercial awareness and can contribute to the production of promotional materials.

\section{Public legal education value}

The disadvantages and limitations of the use of blogs as a method of public legal education are explored in part 4, but let us first consider some of the advantages. The public legal educational value of a blog is that, like Street Law and similar initiatives, it can be used to educate the public about the law and how it affects them. Students, under the supervision of a lecturer, can write about legal issues, and legal updates. Blogs tend to be written in an informal, concise style, avoiding jargon and legalese. This style is complimentary to a public legal education mission that is driven by the need to make legal issues and information as accessible as possible to lay people. Also, as demonstrated by the Northumbria case study, blogs published on the internet and available for anyone to access can potentially reach a very wide audience. Rather than being limited to a particular geographic area or even a specific country, a blog post can be read by anyone, anywhere in the world who has access to an internet enabled device or computer. The United Nation's agency for information communication technology, the ITU, suggests that in developed countries 
$81 \%$ of the population use the internet $(94.3 \%$ of $15-24$ year olds) and in developing countries $41.3 \%$ (67.3\% of $15-24$ year olds) use the internet. ${ }^{45}$ In the UK, the most recent Office of National Statistics data suggests that $89 \%$ of people use the internet regularly putting the UK slightly above the average for a developed country. ${ }^{46}$

Blogs also appear to be cost effective from a university perspective. The Blog project discussed in our case study did not involve any costs and one of the advantages of blog sites like WordPress are that they are free and easily accessible. ${ }^{47}$ A blog which is truly student-led should also be time efficient, likely involving less hours and resources than face-to-face public legal education. Students do not need to undergo any training to write a blog post (our students normally find it sufficient to read prior posts) and they can choose when they want to get involved, making it easier to fit around their other commitments.

\section{Challenges and Limitations of using Blogs as a Teaching Tool and Method of Public Legal Education}

Staff development and time constraints

\footnotetext{
${ }^{45}$ See http://www.itu.int/en/ITU-D/Statistics/Documents/facts/ICTFactsFigures2017.pdf (accessed 24 November 2017).

46

https://www.ons.gov.uk/businessindustryandtrade/itandinternetindustry/bulletins/internetuser s/2017 (accessed 24 November 2017).

${ }^{47}$ Whilst all are free to establish a basic account some do charge for premium services or functionality.
} 
Whilst social media may have a range of pedagogical uses, Rambe and Nel have highlighted that any 'utopian' views about social media do not necessarily reflect the reality facing educators. ${ }^{48}$ Interaction with technology is more complex than this and there are possibly a number of barriers, or perceived barriers, to the incorporation of social media within teaching. ${ }^{49}$ An obvious challenge in using social media as a teaching tool is that some staff may not be familiar with the technology or, to use Prensky's terminology, they may be 'digital immigrants' rather than 'digital natives'.$^{50}$ Whilst Black suggests it does not take long to master the requisite technology ${ }^{51}$ and we have found applications like WordPress easy to use, it is acknowledged that this is a valid concern. The author agrees with Kukulska-Hulme though who argues that academics should commit to their own life-long learning and try to adapt to a world saturated with social technologies. ${ }^{52}$ It is clear to do so they will need institutional support and guidance. One issue is that institutions may be reluctant to provide such

\footnotetext{
${ }^{48}$ P. Rambe and L. Nel, 'Technological utopia, dystopia and ambivalence: Teaching with social media at a South African university' (2015) 46 British Journal of Educational Technology 629 at pp. 644-645.

${ }^{49}$ Ibid.

50 M. Prensky, 'Digital Natives, Digital Immigrants' (2001) 9(5) On the Horizon 1, p. 2.

${ }^{51}$ P. Black, 'Uses of blogs in legal education' (2006) 13 James Cook University Law Review 8 at p. 21.

${ }^{52}$ A. Kukulska-Hulme, 'How should the higher education workforce adapt to advancements in technology for teaching and learning?' (2012) 15 The Internet and Higher Education 247 at p. 253.
} 
support and guidance due to concerns about the lack of control the institution might have over such open platforms. ${ }^{53}$

Academics also face increasing pressure on their time and, unsurprising, the time required to effectively incorporate social media enhanced tasks into teaching was raised as a concern in a 2015 study of educators' experiences of using various social media. ${ }^{54}$ As the amount of time involved will depend on the type of social media employed and how much interaction/maintenance is required from the relevant academic, it is important to bear these practical considerations in mind at the design stage. Although, as noted above, once familiar with the relevant technology, a student-led blog should not be overly time consuming to maintain. Perhaps having assessed, rather than voluntary, projects may be preferable as well because at least then the lecturer should be formally allocated teaching hours.

\section{Student acceptance}

Another related issue identified by Krause and reiterated by Black is that just because you give students the opportunity to use technology does not

\footnotetext{
${ }^{53}$ As suggested in $\mathrm{D}$. $\mathrm{Ng}$ ' Ambi, 'Effective and ineffective uses of emerging technologies: Towards a transformative pedagogical model' (2013) 44 British Journal of Educational Technology 652 at p. 660.

${ }^{54}$ P. Rambe and L. Nel, 'Technological utopia, dystopia and ambivalence: Teaching with social media at a South African university' (2015) 46 British Journal of Educational Technology 629 at 641.
} 
mean they will want to use it. ${ }^{55}$ Whilst many of our students have engaged with the Blog, a significant number who have been given the opportunity to participate have not done so. To ensure the teaching remains as inclusive as possible, it is probably best not assume all students will be familiar with blogs. Academics need to bear in mind that there may be cost implications for students too in terms of equipment and access to the internet, particularly where students are expected to participate off campus. This is likely to be a greater issue for institutions in resource-poor settings as Rambe and Nel have highlighted. ${ }^{56}$ This is not a concern if, as we do, lecturers deal with the maintenance of the blog.

\section{Slipping standards?}

Selwyn and Grant suggest that some academics may resist the use of social media out of a belief it could have negative effect on traditional skills and literacies. ${ }^{57}$ It is probably correct to say that the language used in social media is generally more informal than that used in academic writing. We have not found this to be an issue with the Blog because, as Black suggests, we provided clear guidelines to students about tone and style and act as

\footnotetext{
55 P. Black, 'Uses of blogs in legal education' (2006) 13 James Cook University Law Review 8 at p. 21 referring to S. Krause, 'Blogs as a Tool for Teaching' (2005) 51(42) The Chronicle of Higher Education B33.

${ }^{56}$ P. Rambe and L. Nel, 'Technological utopia, dystopia and ambivalence: Teaching with social media at a South African university' (2015) 46 British Journal of Educational Technology 629 at p. 640.

${ }^{57}$ N. Selwyn and L. Grant. 'Researching the realities of social software use-an introduction'. Learning, Media and Technology, 34 (2), 79 at pp. 80-81.
} 
editors. ${ }^{58}$ Plagiarism has also been raised as a potential fear with students 'research[ing] by google' or to plagiarise by copying and pasting material from elsewhere. ${ }^{59}$ Again, the author agrees with Black that a lecturer can counter this by outlining a clear policy as to what is expected in terms of research and referencing.

From a public legal education perspective the informality referred to above, is actually likely to be beneficial. The intended audience is far more likely to relate to, and understand, information written in an unfussy, plain English style after all. Some caution is needed though as over simplistic explanations could lead to confusion. This is why we take the view that, even where a student has followed referencing policies, it is prudent for us to act as editors and check the law and the clarity of the explanations.

A poor substitute for Street Law?

It is acknowledged that educating others through face-to-face interactions, such as is advocated in traditional Street Law programmes, has a number of advantages over online content in blogs. Firstly, when teaching is delivered in person, there is much greater scope for judging understanding, modifying delivery if things are not working, and making changes to future delivery according to past experience. None of this is really possible with a

\footnotetext{
${ }^{58}$ P. Black, 'Uses of blogs in legal education' (2006) 13 James Cook University Law Review 8 at $\mathrm{p}$. 22 ${ }^{59} \mathrm{lbid}$.
} 
blog. A blog is also perhaps less interactive than some other forms of social media and there are limited opportunities to obtain feedback (discussed further below). On the other hand, a blog could complement other forms of public legal education or clinical work, and might be useful where these other types of programme are not possible due to time or budgetary constraints.

A poor substitute for bespoke legal advice?

Like some other forms of public legal education, a blog is not, nor intended to be, a substitute for advice from a qualified legal professional and there will be times when a person or business needs to obtain bespoke advice. Our Blog includes a statement confirming that it is intended for general information only and that readers should obtain professional advice before taking, or refraining to take, any action. Arguably though, public legal education can still have an important role in educating people about legal matters on a more general level, informing them about their legal rights and responsibilities, and helping them to identify legal issues they need to seek help with.

How effective is this form of public legal education?

Whilst the data cited above suggests the majority of people in the UK regularly use the internet, not everyone uses the internet in the same way and some groups will be far more adept at searching and locating useful 
information than others. A blog, promoted using social media, might be a good way of getting information to school children, but much less effective at educating the elderly or targeting groups with low levels of literacy. Additionally, while a blog post can be read by anyone in the world who has access to the internet, the legal information in question may be jurisdiction specific and therefore not relevant, or even misleading, to some readers if this is not made clear.

The nature of a blog also makes it difficult to evaluate its effectiveness as a method of public legal education. It is not possible to physically hand out questionnaires to people who read a blog post in the way that you might after face-to-face teaching. Whilst we know how many views the Blog has had, and how many views each post has had, we do not know how useful readers find the blog or what kind of background they come from (student, business person, academic etc.). In fact, geographic location of visitors aside, we know nothing about who is reading the Blog unless someone contacts us directly after a reading a post (which has happened on occasion). More information might be gleaned from activating the comments function of a blog, but this is still an unreliable way of collecting data. The best way of collecting data would probably be to include some kind of survey on the Blog itself, a link to such a survey, or a downloadable questionnaire with instructions to send it to a specific email address. The response rate would 
likely be significantly lower than in a face-to-face environment though, so the data obtained might not be representative of the blog readers as a whole.

\section{Conclusions}

The author regards the Blog project as a success from the perspective of building a collaborative learning environment which allows students to select their own learning topics and build their own knowledge. A number of academics believe that blogs and social media more generally can have an educational value for students but further empirical studies are perhaps required to test this hypothesis further. Blogs should never replace face-to-face teaching but they may be able to complement more traditional forms of learning. Likewise, blogs should not replace valuable public education initiatives like Street Law, but they could supplement such projects or be employed where such projects are not possible. The principal advantages of blogs are that they are relatively cheap and easy to set up and maintain and can reach a wide audience.

The use of blogs warrants careful planning and consideration. Academics should ensure that the teaching design is inclusive and does not inadvertently invade a student's privacy. Particular thought needs to be given to any use of social media where participation is mandatory and students are required to have a public profile they may not be comfortable 
with. It is recommended that lecturers spend time planning and considering the time required to set up and maintain teaching involving blogs. Where a teaching team involves a number of lecturers, it must be remembered that some may not be comfortable with the technology and this form of teaching. A successful project will require buy in from all involved. The author also recommends that consideration is given at outset to what the project's aims are and how its success will be measured. It seems sensible to ask students to provide feedback, including those who did not engage to find out the reasons why. Obtaining data from the readers of the blog, and measuring the value of the blog in furthering public legal education, is particularly tricky. Discussion needs to revolve about how such data might be gathered and whether enough responses are received to make the data useful.

Ideally, best practice exemplars for working with blogs and other social media should be disseminated by institutions ${ }^{60}$, training provided and policies dealing with ethical matters published. If institutions are reluctant to endorse the use of social media, the author suggests that it would still be better to introduce policies and guidelines rather than ignore it. To do so risks piecemeal and inconsistent adoption, and risks unexpected problems arising. Perhaps both institutions and lecturers might heed the advice of

\footnotetext{
${ }^{60} \mathrm{P}$. Rambe P and Nel L, 'Technological utopia, dystopia and ambivalence: Teaching with social media at a South African university' (2015) 46 British Journal of Educational Technology 629 at p. 644.
} 
IJPLE 2 (1) 2018

Siemens and Tittenberger that teaching with technologies requires 'a spirit of experimentation' and a 'tolerance of failure'.$^{61}$

${ }^{61} \mathrm{G}$. Siemens and P. Tittenberger, Handbook of emerging technologies for learning. (University of Manitoba, 2009) at p. 15. 